\title{
Valley Wind Revealed by Wind-shaped Trees at Kali Gandaki Valley*
}

\author{
Tetsuo Ohata** and Keiji Higuchi**
}

\begin{abstract}
Strong valley winds of 10 to $15 \mathrm{~m} / \mathrm{sec}$ were observed in the daytime during a stay in the Kali Gandaki Valley in November, 1976. This valley wind, which seems to exist throughout the year, is studied using the wind-shaped trees in this valley as an index. The wind-shaped trees which were most strongly deformed were found between Larjung and Jomson. In other regions some moderately deformed wind-shaped trees were found at places with local topography favorable for their formation. Deformation was weak in the tributaries of the Kali Gandaki.
\end{abstract}

\section{Introduction}

In the Himalayas, there are many valleys running down at a right angle from the high mountain ranges. In some of these valleys, occurences of strong valley winds have been reported (Flohn 1966, Flohn 1970). These winds have great influence on the formation of clouds and energy exchange in the valleys and in the glaciated mountain areas.

In this paper, the valley wind in the Kali Gandaki Valley will be investigated, by the use of windshaped trees as an index, since windshaped trees are a good index in investigating the characteristics of the wind in a valley, as can be seen in the work of Yoshino (1964) in the Rhone Valley in Switzerland.

\section{Observation site and method}

Kali Gandaki Valley is located in the central part of Nepal, northwest of Pokhara. Kali Gandaki originates at the Tibetan border and flows southward to the hilly regions. The valley is approximately $110 \mathrm{~km}$ in length and $35 \mathrm{~km}$ in width. The area where the observation were carried out is located in the central part of this long valley, as is shown in Fig. 1. This part of the valley lies between two high mountain ranges, Dhaulagiri to the west and Annapurna to the east.

The observations of the wind-shaped trees were

* Glaciological Expedition of Nepal, Contribution No. 49

** Water Research Institute, Nagoya University, Nagoya 464 made by taking photographs and determining the direction of the formation, for trees near the route we took. Trees that were not accessible were sketched with the aid of binoculars.

\section{Observational results}

In the valley many types of trees were found, coniferous trees such as Juuiperus and Piuus, and some broadleaf trees. The trees were classified into only two types, coniferous trees and broadleaf trees, for not all of the names of the trees were known.

The degree of deformation of the wind-shaped trees were classified into 4 grades, applying the classification established by Yoshino (1973). The classification is shown in Table 1. Grade 0 shows trees without deformation; grade 1 trees with little deformation; grade 2, moderate deformation; and grade 3 , severe deformation.

The results of the observation are shown in Fig. 1. The trees chosen for study were those that were deformed most in a small area. Each tree is marked by a circle, and the degree of deformation and the direction of the wind responsible for the deformation are shown by a flag. Open circles shows the broadleaf trees and dark circles show coniferous trees. Photographs of the wind-shaped trees are shown in Fig. 2. Fig. 2a shows one of the trees which was deformed most, its position being No. 18 in Fig. 1. Most branches of the tree are growing on one side only, the leeward side of the prevailing wind. Fig. $2 b$ shows the tree at position No. 11 .

The observation area along Kali Gandaki can be 


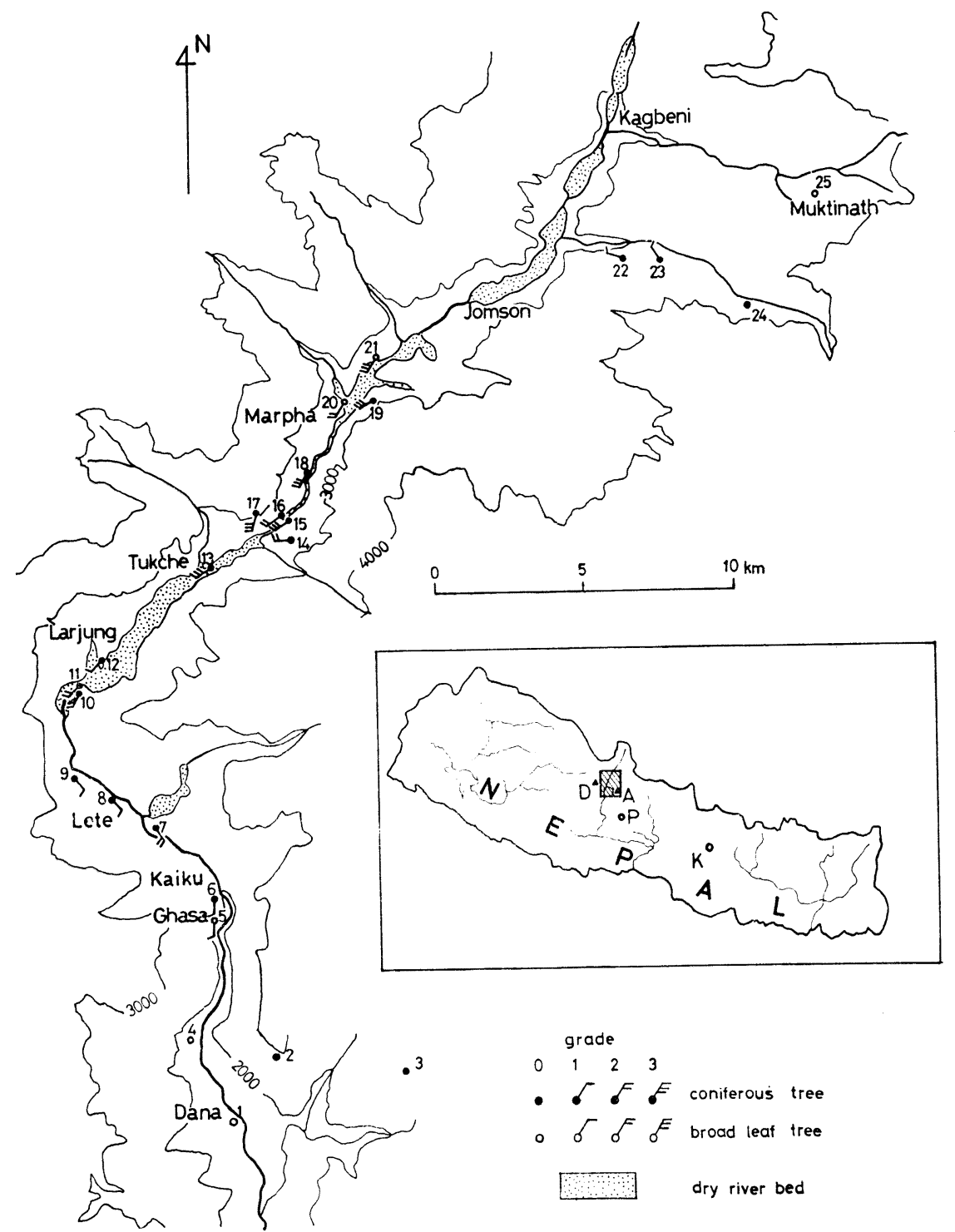

Fig. 1. Distribution of wind-shaped trees along Kali Gandaki Valley. The letters in the map of Nepal stands for the following, K; Kathmandu, P; Pokhara, D; Dhaulagiri, A; Annapurna, The observation area is marked by hatched lines in the small map.

divided into three regions. The main valley can be divided into two parts, below Larjung (region 1) and above Larjung (region 2). In region 1 the valley is oriented in the SW-NE direction, and in region 2 in the SSE-NNW direction. Also the general topography of the valley is different, as shown in Fig. 3. The bottom of the valley at Kaiku, which represents region 1 , has a V-shaped valley floor, compared with a U-shaped valley at Marpha, which represents region 2.

The area along the tributaries to the southeast of Kagbeni will be noted as region 3 .

In the lower part of region 1 (below Kabre), wind-shaped trees were not observed in the valley nor on the slopes. In the upper part of region 1 (above Kabre), trees of grades 1 and 2 were observed. In that part, two sites with trees of grade 2 were found.

In re zion 2 , the most strongly deformed trees were found. In this region, wind-shaped trees were found not only on the valley floor but also on th? side slopes, $300-400 \mathrm{~m}$ above the valley 
Table 1. Classification of the wind-shaped trees for coniferous and broadleaf trees. At the right column, it is shown to which grade in Yoshino's (1973) classification each corresponds.

\begin{tabular}{c|l|l|c} 
grade & \multicolumn{1}{|c|}{ coniferous tree } & broadleaf tree & $\begin{array}{l}\text { Yoshino's (1973) } \\
\text { classification }\end{array}$ \\
\hline 0 & symmetrical form & symmetrical form & 0 \\
\hline 1 & $\begin{array}{l}\text { tree-top and twigs are } \\
\text { bent slightly to leeward }\end{array}$ & $\begin{array}{l}\text { trunk and branches are } \\
\text { bent slightly to leeward }\end{array}$ & 1 \\
\hline 2 & $\begin{array}{l}\text { imperfect flag shaped } \\
\text { tree, up to 2/3 of the } \\
\text { height of the tree from } \\
\text { the treetop is bent to } \\
\text { leeward }\end{array}$ & $\begin{array}{l}\text { trunk and branches up } \\
\text { to 2/3 of the height of } \\
\text { the tree is bent to lee- } \\
\text { ward }\end{array}$ & $2 \& 3$ \\
\hline 3 & $\begin{array}{l}\text { perfect flag-shaped tree, } \\
\text { all branches are bent } \\
\text { toward leeward }\end{array}$ & $\begin{array}{l}\text { trunk and branches are } \\
\text { almost perfectly bent to } \\
\text { leeward, on windward } \\
\text { side trunk is bare }\end{array}$ & 4 \\
\hline
\end{tabular}

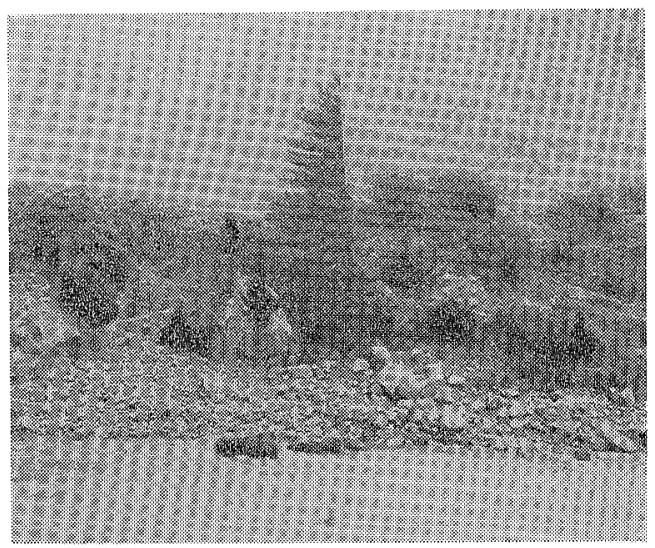

(a)

floor (Nos. 14, 17, 19 in Fig. 1).

The climate above Jomson is arid, the annual rainfall amount being less than $300 \mathrm{~mm} / \mathrm{yr}$ (Dept. of Hyd \& Met, HMG, Nepal). For this circumstances, only a few trees which were adequate for observations of wind-shaped trees were found.

Four sites in region 3 are plotted in Fig. 1 (Nos. 22-25). Two of them showed deformation of grade 1 and the remainder of grade 0 . The direction of the deformation was nearly parellel to the direction of the small tributaries.

The direction of deformation of trees was to the upstream side of the tree at about all sites. This means that the wind responsible for the deformation is the upvalley wind. Few exceptions were seen at the sites on the side slopes of the valley (Nos. 14, 17, 19 in Fig. 1). The direction of the deformation of these trees were at an angle with the direction of

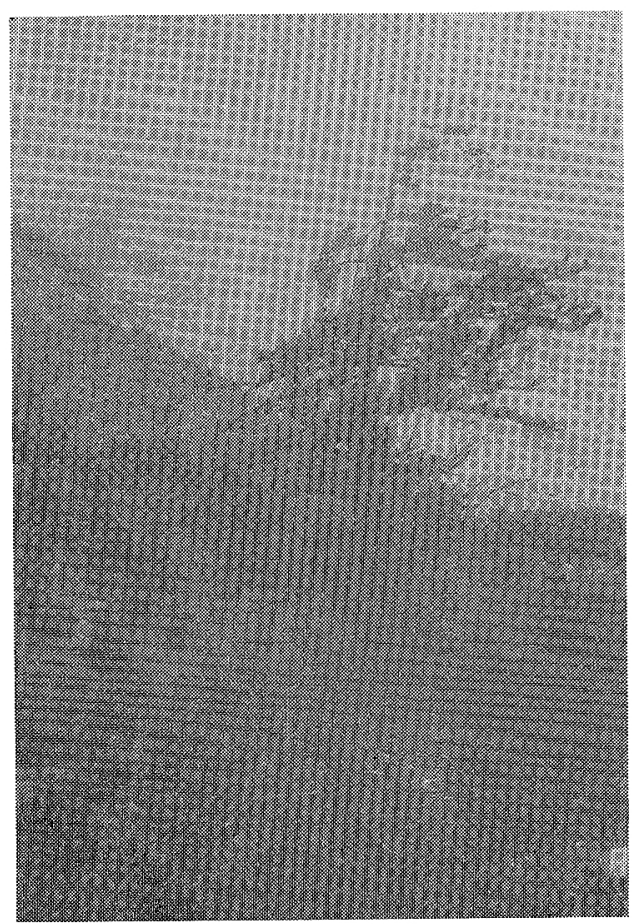

(b)

Fig. 2 Photographs of wind-shaped trees (a) No. 18 in Fig. 1, grade 3.

(b) No. 11 in Fig. 1, grade 2.

the main valley.

Complete data of wind in this valley are not available. During the stay at the valley in November 1976, strong upvalley winds up to $15 \mathrm{~m} / \mathrm{sec}$ were observed in the daytime at Tukche and Jomson. After 2000 or 2100 LT in the nightime, this upvalley 


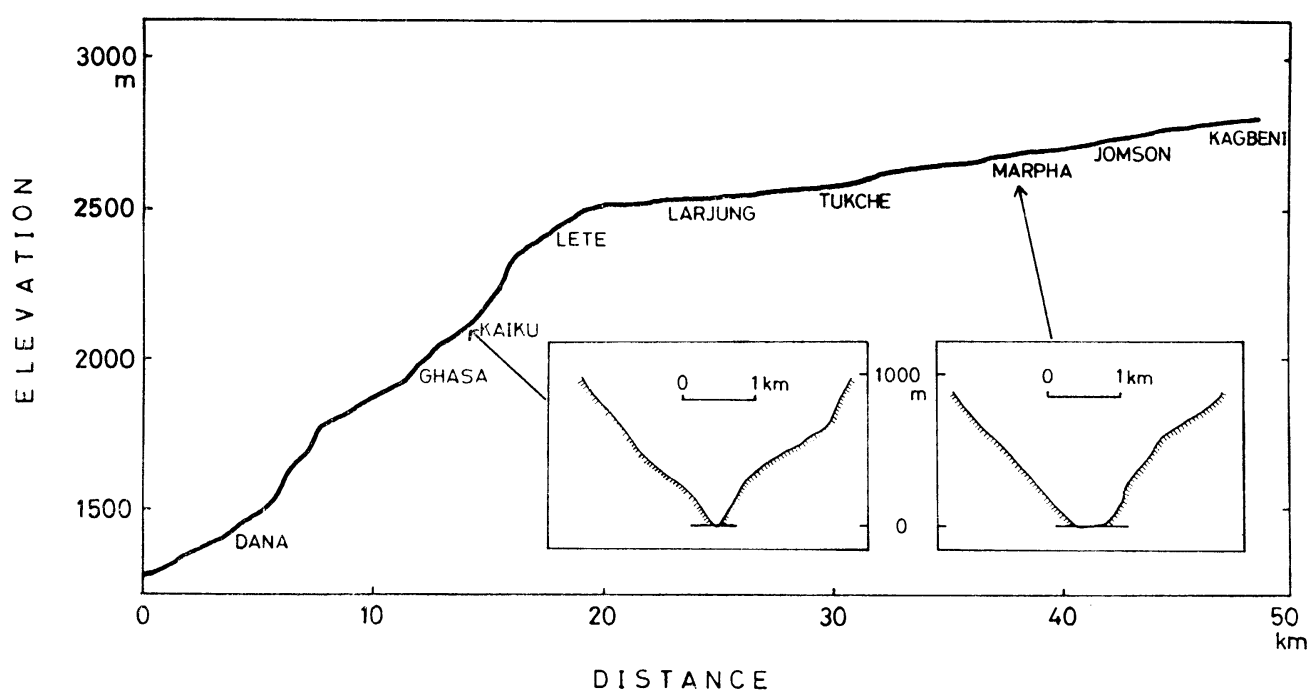

Fig. 3. Elevation of the valley bottom along Kali Gandaki, and the cross section of the valley at Kaiku in region 1 and Marpha in region 2.

wind ended and became calm. In the morning the wind was downvalley but weak. The people there also commented on the strong upvalley wind in this valley in the daytime throughout the year. From these facts, it can be concluded that in this valley the prevailing wind is the valley wind which blows throughout the year. This is the same situation as in Khumbu Region, Eastern Nepal, which is reported by Inoue (1976).

\section{Discussion}

From the direction of the deformation of the wind-shaped trees and the comment on the wind in the valley in the previous section, the wind system that contributes to the wind-shaped trees in this area can be concluded to be the valley wind.

Stormy valley winds such as observed here and in other valleys in Himalayas (sec. 1) are, firstly, the result of strong insolation, as the altitude of this area is quite high (the bottom of the valley being 1500-3000 $\mathrm{m}$ a.s.l.) and the latitude is in the sub-tropical zone. Other factor such as the largeness of the valley will have effect.

The upvalley wind system may not be a local valley wind confined inside the valley but a valley wind superimposed on the large scale wind system described by Flohn (1968). The large scale wind system around the Tibetan Plateau up to $500 \mathrm{mb}$ converges toward the plateau, which implies a southerly component above Kali Gandaki Valley. Due to this, the apparent wind will be strengthened in this area.
Next, the regional difference in wind-shaped trees which show the difference in the strength of the valley wind at tree level can be discussed in relation to the topographical and surface conditions.

In the upper part of region 1, two sites had moderate deformation of grade 2 . These can be explained by the intensification of wind due to local topography. One (No. 11 in Fig. 1) was located at the end of a ridge which came down into the floor of the valley. At that point the valley floor narrowed considerably due to the ridge. The wind converges at that point and gives rise to a strong wind. The other site (No. 7 in Fig. 1) was located at the top of a terrace elevated $50 \mathrm{~m}$ above the river. At that point, the river changes its direction of flow along the terrace from NW to WNW, looking upvalley. Therefore the wind coming up the valley will blow up along the slope of the terrace and onto the terrace. Due to the convergence of the flow, the wind at the edge of the terrace becomes strong. From these facts, it can be stated that moderately deformed windshaped trees in region 1 were found only where conditions are favorable for the convergence of the upvalley wind.

Therefore it can be considered that the mean strength of valley wind at tree level is stronger in region 2 than in region 1 .

The weakness of the valley wind in region 3 , the tributaries of the main valley can be easily understood. The reason is that these valleys are 
short and these direction is at a large angle to the main valley.

The difference between region 1 and 2 is complicated. This should be discussed from two points of view. One is the strength of the wind at tree level, and the other is the scale and strength of the valley wind system in the two regions.

From the first point of view, it can be said that in region 2, the bottom of the valley is very flat, and the roughness of the valley floor is small, because above Larjung most of the valley floor is dry river bed without much tall vegetation. In contrast, region 1 is covered with much tall vegetation. This difference in the condition of the surface will lead to a stronger tree level wind at region 2 .

From the second point of view, no accurate explanation can be given at this time, due to the lack of observations. However, there are a few condition that may have effect on the difference of scale and strength of the valley wind in region 1 and 2. They are

(a) Regions 1 and 2 of the valley are oriented in different directions, SSE-NNW for region 1 and SW-NE for region 2.

(b) The average inclination of the valleys is different as seen in Fig. 3.

(c) The shapes of the valleys are different in the two regions, as seen in Fig.3. Region 2 is a U-shaped valley with a wide valley floor, compared with a $\mathrm{V}$-shaped valley in region 1 (d) The difference in the thermal response of the ground surface due to the difference in the amount of the vegetation.

(e) As the elevation of region 2 is higher, the large scale circulation will have stronger effect on the valley wind of this region.

The above items (c), (d) and (e) will probably have an effect in strengthening the valley wind in region 2. However, the effect of (a) and (b) can not be estimated at this moment.

\section{References}

Flohn, H. 1966; Local wind system, in World Survey of Climatology, 2, p. 139-171, Elsevier Pub. Co. Amsterdam.

Flohn, H. 1968; Contribution to a Meteorology of the Tibetan Highlands, Colorado State Univ. Sc. Paper, 130, p. 120.

Flohn, H. 1970; Beiträge zur Meteorologie des Himalaya, Khumbu Himal Band 7, p. 25-45.

Inoue, J. 1976; Climate of Khumbu Himal, Glaciers and Climates of Nepal Himalayas, Seppyo, 38, Special Issue, p. 66-73.

Yoshino, M.M. 1964; Some local characteristics of the winds as revealed by wind shaped trees in the Rhone Valley in Switzerland, Erdkunde, 18, p. 28-38.

Yoshino, M.M. 1973; Studies on wind-shaped trees: their classification, distribution and significance as a climatic indicator, Climat. notes, Hosei Univ. No. 12 , p. 1-52. 